\title{
Design and Rationale of a Scandinavian Multicenter Randomized Study Evaluating if Once-Daily Tacrolimus Versus Twice-Daily Cyclosporine Reduces the 3-year Incidence of Chronic Lung Allograft Dysfunction After Lung Transplantation (ScanCLAD Study)
}

Göran Dellgren · Thomas Kromann Lund · Peter Raivio •

Inga Leuckfeld · Johan Svahn · Jesper Magnusson • Gerdt C. Riise

Received: September 20, 2019/ Published online: January 28, 2020

(c) The Author(s) 2020

\section{ABSTRACT}

Background: A low level of evidence exists regarding the choice of calcineurin inhibitor (CNI) for immunosuppression after lung transplantation (LTx). Therefore, we designed a randomized clinical trial according to good clinical practice rules to compare tacrolimus with cyclosporine after LTx.

Methods: The ScanCLAD study is an investigator-initiated, pragmatic, controlled, randomized, open-label, multicenter study evaluating if an immunosuppressive protocol based on anti-

Enhanced Digital Features To view enhanced digital features for this article go to https://doi.org/10.6084/ m9.figshare.11523213.

\footnotetext{
G. Dellgren $(\bowtie)$

Department of Cardiothoracic Surgery, Sahlgrenska, University Hospital, Gothenburg, Sweden

e-mail: goran.dellgren@vgregion.se

G. Dellgren · J. Magnusson · G. C. Riise

Transplant Institute, Sahlgrenska, University

Hospital, Gothenburg, Sweden

J. Magnusson · G. C. Riise

Pulmonology, Sahlgrenska, University Hospital,

Gothenburg, Sweden

T. K. Lund

Section for Lung Transplantation, Rigshospitalet,

University Hospital of Copenhagen, Copenhagen,

Denmark
}

thymocyte globulin (ATG) induction, once-daily tacrolimus dose, mycophenolate mofetil, and corticosteroid reduces the incidence of chronic lung allograft dysfunction (CLAD) after LTx, compared to a cyclosporine-based protocol with all other immunosuppressive and prophylactic drugs being identical between groups. All patients will be followed for 3 years to determine the main endpoint of CLAD. The study is designed for superiority, and power calculations show that 242 patients are needed. Also, the study is designed with more than 10 substudies addressing other important and unresolved issues in LTx. In addition, the ScanCLAD study enabled the synchronization of the treatment and follow-up protocols of the lung transplantation programs of all five Scandinavian lung transplantation centers.

\footnotetext{
P. Raivio

Department of Cardiac Surgery, Heart and Lung Center, Helsinki University Hospital, Helsinki, Finland

I. Leuckfeld

Department of Respiratory Medicine, Oslo

University Hospital, Oslo, Norway

J. Svahn

Department of Pulmonology, Lund University

Hospital, Lund, Sweden
} 
Planned Outcomes: Recruitment started in 2016. At the end of April 2019, 227 patients were randomized. We anticipate the last patient to be randomized in autumn 2019, and thus the last patient visits will be in 2022 . The ScanCLAD study is enrolling and investigates which $\mathrm{CNI}$ is to be preferred from a CLAD perspective after LTx.

Trial Registry Number: ScanCLAD trial registered at ClinicalTrials.gov before patient enrollment (NCT02936505). EUDRACT number 2015-004137-27.

Keywords: Lung transplantation; Calcineurin inhibitor; Chronic lung allograft dysfunction; Randomized clinical trial

\section{Key Summary Points}

Why carry out this study?

A calcineurin inhibitor $(\mathrm{CNI})$ is considered essential after lung transplantation (LTx) but few randomized controlled trials (RCT) exploring the differences between cyclosporine and tacrolimus exist in LTx.

Therefore, we wanted to test whether chronic lung allograft dysfunction (CLAD) would be more prevalent with cyclosporine or tacrolimus in a RCT.

The ScanCLAD study is an investigator initiated, pragmatic, controlled, randomized, open-label, multi-center study evaluating if an immunosuppressive protocol based on ATG-induction, once daily tacrolimus-dose, mycophenolate mofetil and corticosteroid reduces the incidence of CLAD after LTx, compared to a cyclosporine-based protocol with all other immunosuppressive and prophylactic drugs being identical between groups.

\section{What was learned from the study?}

The ScanCLAD study is enrolling and investigates which CNI is to be preferred from a CLAD perspective after LTx.

The ScanCLAD study is designed with more than 10 sub-studies addressing other important and unresolved issues in LTx..

\section{INTRODUCTION}

A calcineurin inhibitor (CNI) is considered essential after lung transplantation (LTx). Both cyclosporine and tacrolimus are used as CNI after LTx. In Scandinavia we have used cyclosporine for a long time, and still do, with good results in LTx $[1,2]$. Few randomized controlled trials (RCT) exploring the differences between cyclosporine and tacrolimus exist in LTx [3], and despite this most centers around the world have switched to tacrolimus [4].

Chronic rejection after LTx is characterized by a decline in lung function and was previously considered equivalent to bronchiolitis obliterans syndrome (BOS). Nowadays chronic rejection is referred to as chronic lung allograft dysfunction (CLAD) [5]. CLAD includes the older description BOS characterized by small airway fibrosis and obstructive lung physiology and a restrictive allograft syndrome (RAS) characterized by parenchymal/pleural fibrosis and a restrictive physiology. The definition of both CLAD and RAS has recently been updated $[6,7]$.

Therefore, in a regular clinical setting where most adult patients undergoing LTx would be eligible for inclusion, we wanted to test whether CLAD would be more prevalent with cyclosporine or tacrolimus.

\section{METHODS}

\section{Study Aim}

The aim of the study is to evaluate whether immunosuppression based on a once-daily tacrolimus dose regimen (Advagraf ${ }^{\circledR}$ ), with antithymocyte globulin (Thymoglobulin ${ }^{\circledR}$ ) induction, mycophenolate mofetil (MMF), and corticosteroids (CS), reduces the cumulative incidence of CLAD after de novo LTx at 36 months, in comparison with a twice-daily cyclosporine-based protocol, with otherwise identical treatment between groups. 


\section{Study Design}

This is an investigator-initiated, prospective, Scandinavian (multinational), multicenter, randomized, controlled, parallel group, and open-label study in de novo lung transplant recipients. Patients fulfilling all of the inclusion and none of the exclusion criteria will be randomized to one of the two treatment groups. Enrollment will be continued until the required sample size is achieved. This multicenter study was first approved by the Ethics Review Board (D.nr 154-16) at the University of Gothenburg as well as by the Medical Product Agency in Sweden (EUDRACT number 2015-004137-27, D.nr 5.1 2016-31518), and subsequently by the corresponding authorities in Denmark, Finland, and Norway. Therefore, ethics committees (EC) of all the Scandinavian countries have approved the final study protocol, including the final version of the informed consent form, and the following amendments of the protocol, including all substudies. In addition, medical product agencies in all four participating countries have approved the study. Written informed consent will be obtained before any study-related procedures are implemented. The study will be performed in accordance with ethical principles that have their origin in the Declaration of Helsinki and are consistent with ICH-GCP and applicable local regulatory requirements. The study was registered at ClinicalTrial.gov (NCT02936505) well before the first patient was included in the study.

\section{Study Objectives and Endpoints}

The primary objective is to compare the efficacy between treatment regimes by assessing the difference in CLAD incidence at 36 months after LTx.

Secondary endpoints are outlined in Table 1. Many of these are the basis for separate substudies.

\section{Study Population}

The study population will consist of a representative group $(n=242)$ of de novo lung transplant patients who fulfill the requirements according to inclusion and exclusion criteria (Table 2). The intention is that it will be possible for most patients eligible for LTx in Scandinavia to be included in the study, with the exception of those undergoing re-transplantation, single lung transplantation, and recipients under the age of 18. The patients are randomized immediately prior to transplantation to receive a standard immunosuppressive protocol of cyclosporine, MMF and CS-group A, or a combination of tacrolimus, MMF, and CSgroup B (Fig. 1). The patients will be recruited from all five Scandinavian centers for lung transplantation: Copenhagen, Denmark; Gothenburg, Sweden; Helsinki, Finland; Lund, Sweden; and Oslo, Norway. Since the study is designed as an "all in study" (however, pediatrics and re-transplantations are excluded), the expected inclusion time was calculated to be 2 years since the annual volume is approximately 140 LTx (mean of 142 LTx during 2012-2016, and stratified by center: Gothenburg 43; Lund 16; Oslo 32; Helsinki 20; and Copenhagen 31) among Scandinavian institutions.

\section{Substudies}

The ScanCLAD study includes a number of separate substudies addressing important and unanswered questions, which are of interest regardless of the outcome of the main study. All substudies are shown in Table 3 . Each substudy has its own responsible principle investigator (PI), and most include patients from all sites. The substudies have separate protocols and budgets.

\section{Clinical Assessment}

All assessments and visits are shown in Table 4 . All the obtained data must be supported in the patient's medical records, i.e., source documentation, and subsequently stored in an electronic case record form (eCRF). Management of immunosuppressive regime of the ScanCLAD study is outlined in Table 5. Azithromycin will 
Table 1 Secondary objectives

To compare the efficacy between treatment regimes by assessing the difference in

Renal function evaluated by mGFR at 3 months after LTx

The composite measure of freedom from allograft rejection, CLAD, graft survival, and patient survival at 12,24 , and 36 months after transplantation

The cumulative incidence of PGD at $72 \mathrm{~h}$

Patient survival at 1 and 3 years

The cumulative incidence of acute allograft rejection and CLAD at 6 months, 1 year, and 3 years

The cumulative incidence of BOS and RAS at 6 months, 1 year, and 3 years

Development of DSA at 12, 24, and 36 months

Renal function evaluated by mGFR, by iohexol or Cr-EDTA clearance, at 12, 24, and 36 months

Renal function evaluated by cGFR, by three different formulas, at 3, 12, 24, and 36 months

The cumulative incidence of PTDM at 6, 12, 24, and 36 months after transplantation

Use of antidiabetic medication at $6,12,24$, and 36 months

Incidence and number of antihypertensive and lipid-lowering drugs at 12, 24, and 36 months

Development and magnitude of proteinuria at 12, 24, and 36 months

Lipid profile at 12, 24, and 36 months

Incidence of CMV that required treatment (CMV infection or CMV syndrome)

Cumulative incidence of malignancy stratified by PTLD and all other cancers, at 36 months

Safety and tolerability

Quality of life, assessed by EQ 5D3L and SGRQ, both self-administered, pre-transplant and at 12, 24, and 36 months

Define the pharmacokinetics of tacrolimus in patients without CF $(n=12)$ and all included patients with CF

$(n=15-20)$ undergoing primary lung transplantation treated with Advagraf ${ }^{\circledR}$-based immunosuppression

Immunological equipotency of tacrolimus and cyclosporine in vivo and in vitro

Occurrence of treatment failures up to or at 36 months; defined as a composite endpoint of graft loss, death, loss to follow-up or discontinuation due to lack of efficacy or toxicity (at least one condition must be present)

Recovery of right heart function irrespective of diagnosis in patients with PAH (categories 1-5 according to WHO $1-5)$

$B O S$ bronchiolitis obliterans syndrome, $C F$ cystic fibrosis, $c G F R$ calculated glomerular filtration rate, $C L A D$ chronic lung allograft dysfunction, $C M V$ cytomegalovirus, DSA donor-specific antibodies, ISHLT International Society of Heart and Lung Transplantation, $L T x$ lung transplantation, $m G F R$ measured glomerular filtration rate, $P A H$ pulmonary arterial hypertension, $R A S$ restrictive allograft syndrome, $P G D$ primary graft dysfunction, $P T D M$ post-transplantation diabetes mellitus, PTLD post-transplant lymphoproliferative disorder, SGRQ St Georges Respiratory Questionnaire, WHO World Health Organization 
Table 2 Inclusion and exclusion criteria

Inclusion criteria

Male or female lung recipients $18-70$ years of age undergoing primary double (including size reduction) lung transplantation

Patient willing and capable of giving written informed consent for study participation and anticipated to be able to participate in the study for 36 months

Exclusion criteria

Recipients of multiorgan transplant, and/or previously transplanted with any organ, including previous lung transplantation

Patients with hypersensitivity to or other reasons to not be able to take the immunosuppressive drugs used in the study

Donor lung cold ischemic time $>12 \mathrm{~h}$

Patients who previously have been treated with anti-thymocyte globulin preparations (e.g., ATG-Fresenius ${ }^{\circledR}$, Thymoglobulin ${ }^{\circledR}$ )

Patients who are recipients of $\mathrm{ABO}$-incompatible transplants

Patients with platelet count $<50,000 / \mathrm{mm}^{3}$ at the evaluation before transplantation

Patients who are unlikely to comply with the study requirements

Patients, and/or those receiving organs from donors, who are positive for HIV, hepatitis B surface antigen, or hepatitis $\mathrm{C}$ virus

Patients with donor older than 75 years

Patient who have received an unlicensed drug or therapy within 1 month prior to study entry or if such therapy is to be instituted post-transplantation

Patient unable to participate in the study for the full 36-month period

Patients with any past (within the past 3 years (low-risk malignancy) to 5 years (high-risk malignancy)) or present malignancy (other than excised basal cell carcinoma)

Women capable of becoming pregnant must have a negative pregnancy test prior to randomization

not be performed as prophylaxis treatment, only when CLAD is suspected or diagnosed.

\section{Efficacy Measurements}

The following efficacy variables will be obtained and recorded:

- Lung function testing: Experienced and skilled technicians in a specialized respiratory laboratory will perform the pulmonary function tests. The quality control and performance of spirometry, measurements of lung volumes, and carbon monoxide uptake (CO uptake), i.e., transfer factor or diffusing capacity (DLCO), are in accordance with the European recommendations [8-10]. Spirometry is performed on a rolling seal spirometer. The forced expiratory vital capacity (FVC) and forced expiratory volume in first second (FEV1) are taken as the highest of repeated recordings. Lung volumes, i.e., total lung capacity (TLC), functional residual capacity (FRC), and residual volume (RV), are obtained in a body plethysmograph. CO uptake is obtained by the single-breath method using standard equipment. Volume and gas concentration 


\section{Scandinavian trial of CLAD after Tacrolimus OD vs Cyclosporin BID in Lung transplantation}

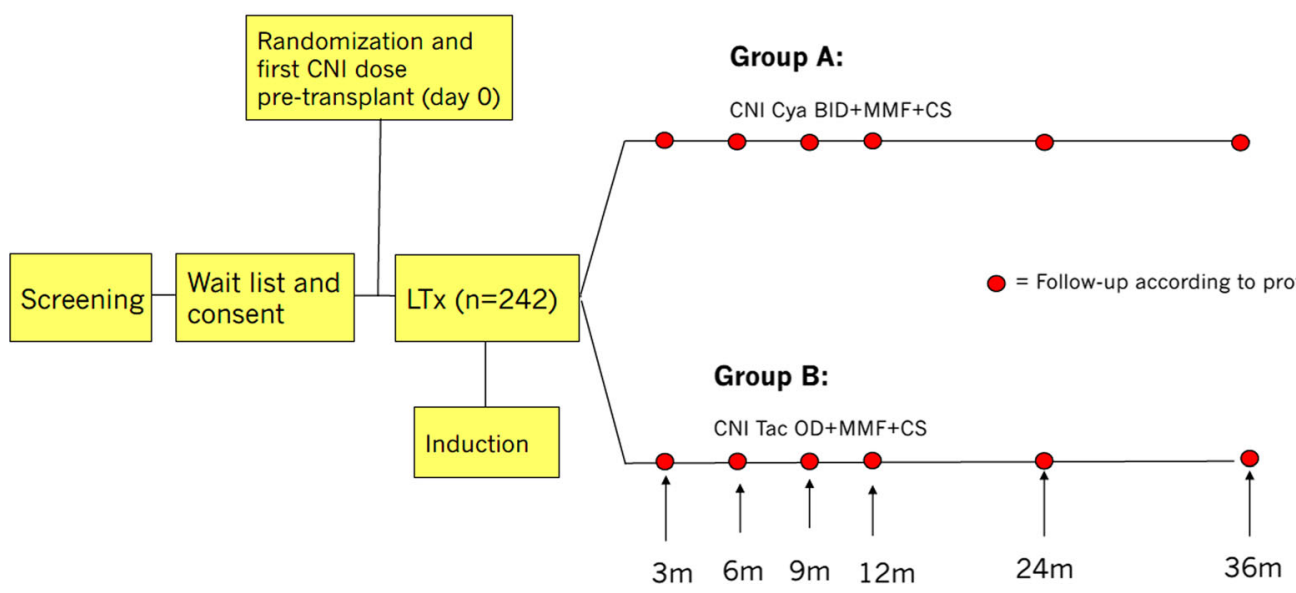

Fig. 1 Design of the ScanCLAD study. LTx lung transplantation, $C N I$ calcineurin inhibitor, Cy $A$ cyclosporine, $B I D$ twice daily, $M M F$ mycophenolate mofetil, $C S$ corticosteroids, Tac tacrolimus, $O D$ once daily

Table 3 Substudies of the main ScanCLAD study

Donor-specific antibodies in chronic lung allograft dysfunction

PTDM in lung transplantation

Equipotency of tacrolimus and cyclosporine in vivo and in vitro

Quality of life after lung transplantation in Scandinavia

Cytomegalovirus as a risk factor for CLAD and its subtypes BOS and RAS

Imaging in primary graft dysfunction

Clinical pharmacokinetics of once-daily prolonged release tacrolimus in cystic fibrosis compared to non-cystic fibrosis lung transplant recipients

Recovery of RV failure in PAH after lung transplantation

Lung donor characteristics as risk factors for PGD and CLAD

Molecular biomarkers as potential targets for therapeutic strategies after lung transplantation

Correlation of the incidence of acute rejection with the non-invasive blood transcriptional assay (SORT)

Weight-to-height ratio as a predictor for CLAD and overall survival after lung transplantation

Cytokines and inflammatory variables in lung-transplanted recipients

AMR in lung transplantation: treatment and risk factors

CLAD subtypes, BOS and RAS, defined by computed tomography volumetry

$A M R$ antibody-mediated rejection, $C L A D$ chronic lung allograft dysfunction, $B O S$ bronchiolitis obliterans syndrome, $P G D$ primary graft dysfunction, PTDM post-transplantation diabetes mellitus, $R A S$ restrictive allograft syndrome 
Table 4 Assessment schedule

\begin{tabular}{|c|c|c|c|c|c|c|c|c|c|c|}
\hline \multirow{2}{*}{$\begin{array}{l}\text { Period } \\
\text { Visit } \\
\text { Week/month }\end{array}$} & \multicolumn{6}{|c|}{ Period 1} & \multicolumn{4}{|c|}{ Period 2} \\
\hline & $\begin{array}{l}1 \\
\text { Pre- } \\
\text { LTx }\end{array}$ & $\begin{array}{l}2 \\
\mathbf{L T} \\
\mathbf{x}\end{array}$ & $\begin{array}{l}3 \\
\mathbf{W} 1\end{array}$ & $\begin{array}{l}4 \\
\text { W4 }\end{array}$ & $\begin{array}{l}5 \\
\text { M3 }\end{array}$ & $\begin{array}{l}6 \\
\text { M6 }\end{array}$ & $\begin{array}{l}7 \\
\text { M9 }\end{array}$ & $\begin{array}{l}8 \\
\text { M12 }\end{array}$ & $\begin{array}{l}9 \\
\text { M24 }\end{array}$ & $\begin{array}{l}10 \\
\text { M36 }\end{array}$ \\
\hline Informed consent & $\mathrm{x}$ & & & & & & & & & \\
\hline Inclusion/exclusion & $\mathrm{x}$ & $\mathrm{x}$ & & & & & & & & \\
\hline Randomization & & $\mathrm{x}$ & & & & & & & & \\
\hline Demography & $\mathrm{x}$ & & & & & & & & & \\
\hline General medical history & $\mathrm{x}$ & & & & & & & & & \\
\hline Transplantation information & & $\mathrm{x}$ & & & & & & & & \\
\hline Background donor & & $\mathrm{x}$ & & & & & & & & \\
\hline Protocol biopsy & & & & $\mathrm{x}$ & $\mathrm{x}$ & & & $\mathrm{x}$ & & \\
\hline HLA typing & $\mathrm{x}$ & & & & & & & & & \\
\hline HLAab/DSA (stored) & $\mathrm{x}$ & & $\mathrm{x}$ & $\mathrm{x}$ & $\mathrm{x}$ & & & $\mathrm{x}$ & $\mathrm{x}$ & $\mathrm{x}$ \\
\hline Vital signs & $\mathrm{x}$ & $\mathrm{x}$ & $\mathrm{x}$ & $\mathrm{x}$ & $\mathrm{x}$ & $\mathrm{x}$ & $\mathrm{x}$ & $\mathrm{x}$ & $\mathrm{x}$ & $\mathrm{x}$ \\
\hline Lung function test Spiro, DLCO, VOL & $\mathrm{x}$ & & & $\mathrm{x}$ & $\mathrm{x}$ & $\mathrm{x}$ & $\mathrm{x}$ & $\mathrm{x}$ & $\mathrm{x}$ & $\mathrm{x}$ \\
\hline 6 min walk test & $\mathrm{x}$ & & & & & & & $\mathrm{x}$ & $\mathrm{x}$ & $\mathrm{x}$ \\
\hline Quality of life & $\mathrm{x}$ & & & & & & & $\mathrm{x}$ & $\mathrm{x}$ & $\mathrm{x}$ \\
\hline \multicolumn{11}{|l|}{ Laboratory test } \\
\hline Hematology/biochemistry & $\mathrm{x}$ & $\mathrm{x}$ & $\mathrm{x}$ & $\mathrm{x}$ & $\mathrm{x}$ & $\mathrm{x}$ & $\mathrm{x}$ & $\mathrm{x}$ & $\mathrm{x}$ & $\mathrm{x}$ \\
\hline Lipid profile & $\mathrm{x}$ & & & & & $\mathrm{x}$ & & $\mathrm{x}$ & $\mathrm{x}$ & $\mathrm{x}$ \\
\hline Viral serology and PCR & $\mathrm{x}$ & & & $\mathrm{x}$ & $\mathrm{x}$ & $\mathrm{x}$ & $\mathrm{x}$ & $\mathrm{x}$ & $\mathrm{x}$ & $\mathrm{x}$ \\
\hline $\begin{array}{l}\text { Flow cytometry ( } \mathrm{T} \text { cell activation) \& ImmunKnow }{ }^{\circledR} \\
\text { assay }\end{array}$ & & & & $\mathrm{x}$ & $\mathrm{x}$ & $\mathrm{x}$ & $\mathrm{x}$ & $\mathrm{x}$ & & \\
\hline Pregnancy test & & $\mathrm{x}$ & & & & & & & & \\
\hline Urinalysis & $\mathrm{x}$ & & $\mathrm{x}$ & $\mathrm{x}$ & & $\mathrm{x}$ & & $\mathrm{x}$ & $\mathrm{x}$ & $\mathrm{x}$ \\
\hline cGFR & $\mathrm{x}$ & & $\mathrm{x}$ & $\mathrm{x}$ & $\mathrm{x}$ & & & $\mathrm{x}$ & $\mathrm{x}$ & $\mathrm{x}$ \\
\hline mGFR & $\mathrm{x}$ & & & & $\mathrm{x}$ & & & $\mathrm{x}$ & $\mathrm{x}$ & $\mathrm{x}$ \\
\hline HR-CT scan & $\mathrm{x}$ & & $\mathrm{x}$ & & $\mathrm{x}$ & & & $\mathrm{x}$ & $\mathrm{x}$ & $\mathrm{x}$ \\
\hline \multicolumn{11}{|l|}{ Drug concentration } \\
\hline Cya/Tac blood conc level & & & $\mathrm{x}$ & $\mathrm{x}$ & $\mathrm{x}$ & $\mathrm{x}$ & $\mathrm{x}$ & $\mathrm{x}$ & $\mathrm{x}$ & $\mathrm{x}$ \\
\hline MPA blood conc level & & & & $\mathrm{x}$ & $\mathrm{x}$ & & & & & \\
\hline Echocardiography in $\mathrm{PAH}$ & $\mathrm{x}$ & & & $\mathrm{x}$ & $\mathrm{x}$ & & & $\mathrm{x}$ & $\mathrm{x}$ & $\mathrm{x}$ \\
\hline DNA/RNA isolation & & $\mathrm{X}$ & $\mathrm{x}$ & $\mathrm{x}$ & $\mathrm{x}$ & $\mathrm{x}$ & & $\mathrm{x}$ & & \\
\hline Tac pharmacokinetics & & & & $\mathrm{x}$ & $\mathrm{x}$ & & & & & \\
\hline
\end{tabular}


Table 4 continued

\begin{tabular}{|c|c|c|c|c|c|c|c|c|c|c|}
\hline \multirow{2}{*}{$\begin{array}{l}\text { Period } \\
\text { Visit } \\
\text { Week/month }\end{array}$} & \multicolumn{6}{|c|}{ Period 1} & \multicolumn{4}{|c|}{ Period 2} \\
\hline & $\begin{array}{l}1 \\
\text { Pre- } \\
\text { LTx }\end{array}$ & $\begin{array}{l}2 \\
\text { LTx }\end{array}$ & $\begin{array}{l}3 \\
\text { W1 }\end{array}$ & $\begin{array}{l}4 \\
\text { W4 }\end{array}$ & $\begin{array}{l}5 \\
\text { M3 }\end{array}$ & $\begin{array}{l}6 \\
\text { M6 }\end{array}$ & $\begin{array}{l}7 \\
\text { M9 }\end{array}$ & $\begin{array}{l}8 \\
\text { M12 }\end{array}$ & $\begin{array}{l}9 \\
\text { M24 }\end{array}$ & $\begin{array}{l}10 \\
\text { M36 }\end{array}$ \\
\hline OGTT & $\mathrm{x}$ & & & & & $\mathrm{x}$ & & $\mathrm{x}$ & $\mathrm{x}$ & $\mathrm{x}$ \\
\hline SORT analysis & $\mathrm{x}$ & & $\mathrm{x}$ & $\mathrm{x}$ & $\mathrm{x}$ & $\mathrm{x}$ & $\mathrm{x}$ & $\mathrm{x}$ & $\mathrm{x}$ & $\mathrm{x}$ \\
\hline Weight-to-height ratio & & $\mathrm{x}$ & & $\mathrm{x}$ & $\mathrm{x}$ & $\mathrm{x}$ & $\mathrm{x}$ & $\mathrm{x}$ & $\mathrm{x}$ & $\mathrm{x}$ \\
\hline Cytokines and inflammatory variables & $\mathrm{x}$ & & $\mathrm{x}$ & $\mathrm{x}$ & $\mathrm{x}$ & $\mathrm{x}$ & & $\mathrm{x}$ & & \\
\hline
\end{tabular}

LTx lung transplantation, $W$ week, $H L A$ human leucocyte antigen, $a b$ antibody, DSA donor-specific antibodies, DLCO diffusing capacity of the lung for carbon monoxide, $V O L$ lung volumes, $P C R$ polymerase chain reaction, $c G F R$ calculated glomerular filtration rate, $m G F R$ measured GFR, HR-CT high resolution computer tomography, Cya cyclosporine, Tac tacrolimus, $P A H$ pulmonary arterial hypertension, DNA deoxyribonucleic acid, $R N A$ ribonucleic acid, OGTT oral glucose tolerance test

calibrations are checked daily. At visits 4 and 7 only spirometry will be performed without volumes or DLCO. The baseline value is defined as the mean of the two best FEV1 values post LTx, from which CLAD will be determined (and FVC will be used to discriminate between BOS and RAS) according to the most updated recommendations [7].

- Measured glomerular filtration rate (mGFR): The mGFR is the best clinical estimate of renal function in health and disease, and correlates well with the clinical severity of renal function disturbances also after transplantation [11]. GFR will be measured using Cr-EDTA clearance or iohexol clearance. The same method should be used throughout the study for a given patient.

- Calculated glomerular filtration rate (cGFR): The GFR calculated according to the MDRD (Modification of Diet in Renal Disease Study Group) method [12, 13] will be used as a secondary outcome measure in this study. The calculated GFR is expressed in $\mathrm{ml} / \mathrm{min}$ per $1.73 \mathrm{~m}^{2}$.

- Rejection episodes and graft loss: All suspected rejection episodes will be recorded in the adverse event (AE) module in the eCRF, whether a biopsy was performed, whether follow-up biopsies were performed, whether anti-rejection therapy was administered, whether the acute rejection was confirmed or with final clinical diagnosis specified, and final clinical outcome.

Biopsy-Proven Acute Rejection

In all suspected rejection episodes, a transbronchial biopsy will be done according to local practice prior to or at the latest within $24 \mathrm{~h}$ after the initiation of antirejection therapy. Biopsies will be read and interpreted by local pathologists. A biopsyproven acute rejection will be defined as a biopsy graded A1-A4 or antibody-mediated rejection according to International Society of Heart and Lung Transplantation (ISHLT) classification [14].

\section{Graft Loss}

Graft loss is considered a serious adverse event (SAE) and should be reported in the SAE module, and the reason for graft loss should be recorded thoroughly.

- Primary graft dysfunction: Primary graft dysfunction (PGD) is defined according to ISHLT definition as pulmonary infiltrates and hypoxemia occurring in the first $72 \mathrm{~h}$ after transplantation [15]. Because chest $\mathrm{x}$-ray has a low sensitivity to detect interstitial changes in transplanted lungs, follow-up will include high-resolution computed tomography 
Table 5 Immunosuppressive regime in the ScanCLAD trial. Patients will be randomized in a 1:1 ratio into two groups, A and $\mathrm{B}$

Group A: cyclosporine A, MMF, and corticosteroids

Induction therapy: Thymoglobulin ${ }^{\circledR}\left(1.5 \mathrm{mg} / \mathrm{kg}\right.$ given immediately postoperatively). Antihistamine (Tavegyl $\left.{ }^{\circledR}\right)$ or similar at a dose of $2 \mathrm{mg}$ iv before induction therapy is initiated

Cyclosporine A: given orally pretransplant at a dose of $2-3 \mathrm{mg} / \mathrm{kg}$

Continued postop day 1 ( $24 \mathrm{~h}$ postoperatively) at a dose of $3 \mathrm{mg} / \mathrm{kg}^{2}$, according to local practice and blood concentration: 0-3 months, 250-300; 3-6 months, 200-250; 6-12 months, 150-200; > 12 months 100-150 ng/ $\mathrm{ml}$. Cyclosporine A will be administered twice daily

MMF target dose $2000 \mathrm{mg} /$ day $(1 \mathrm{~g} \times 2)$

Controlled by a single area under the curve (AUC) measurement on day 90 with a target AUC between 40 and $60 \mathrm{mg} \mathrm{h} / \mathrm{L}$ and corrected accordingly

\section{Corticosteroids}

Day 0 (day of lung transplantation); $500+500 \mathrm{mg}$ methylprednisolone iv before reperfusion, i.e., restoration of blood flow into the transplanted allograft

From day 1 : Initiated at $0.2 \mathrm{mg} / \mathrm{kg} /$ day; tapered to $0.1 \mathrm{mg} / \mathrm{kg} / \mathrm{day} 1-6$ months; less than $0.1 \mathrm{mg} / \mathrm{kg} / \mathrm{day}$ $>3-6$ months

Group B: tacrolimus (Advagraf ${ }^{\circledR}$ ), MMF, and corticosteroids

Induction therapy: Thymoglobulin ${ }^{\circledR}\left(1.5 \mathrm{mg} / \mathrm{kg}\right.$ given immediately postoperatively). Antihistamine (Tavegy $\left.{ }^{\circledR}\right)$ or similar should be started at a dose of $2 \mathrm{mg}$ iv before induction therapy is initiated

Tacrolimus (Advagraf ${ }^{\circledR}$ )

Tacrolimus should be given orally pretransplant at a dose of $0.05-0.1 \mathrm{mg} / \mathrm{kg}$

Continued postop day 1 ( $24 \mathrm{~h}$ postoperatively) at a dose of $0.1-0.2 \mathrm{mg} / \mathrm{kg} / 24 \mathrm{~h}$. To allow tacrolimus blood concentrations to stabilize, Adport ${ }^{\circledR}$ (or any tacrolimus galenic form) should be ordered BiD for the first 3-7 days, or prolonged if long ICU stay is required, and patient should be switched to the investigational drug Advagraf ${ }^{\circledR}$ $\mathrm{OD}$ at the ward or just prior to being discharged from ICU, and subsequently managed according to blood concentration levels: $0-3$ months, $10-14,3-6$ months, $8-12 ; 6-12$ months, $8-10 ;>12$ months, $6-8 \mathrm{ng} / \mathrm{ml}$

MMF target dose $2000 \mathrm{mg} /$ day $(1 \mathrm{~g} \times 2)$

Controlled by a single AUC measurement day 90 with a target AUC between 40 and $60 \mathrm{mg} \mathrm{h} / \mathrm{L}$ and corrected accordingly

Corticosteroids

Day 0; $500+500 \mathrm{mg}$ methylprednisolone iv before reperfusion, i.e., restoration of blood flow into the transplanted allograft

From day 1: initiated at $0.2 \mathrm{mg} / \mathrm{kg} / \mathrm{day}$; tapered to $0.1 \mathrm{mg} / \mathrm{kg} / \mathrm{day} 1-6$ months; less than $0.1 \mathrm{mg} / \mathrm{kg} / \mathrm{day}$ $>3-6$ months 
(HR-CT) on day 3 at definition of PGD and subsequent follow-up at months 3 and 12 where bronchoscopy with transbronchial biopsy (TBB) is available for correlation study. A validated scoring system, which has been used in a previous prospective study of PGD, will be applied $[16,17]$.

- Measurements of inflammatory variables: Cytokines and other inflammatory variable will be analyzed in plasma/serum enzyme immunoassays or Luminex multiplex assay. Serum and plasma samples will be taken before transplantation, at 1,4 , and 12 weeks, and at 6 and 12 months post-transplant and cryopreserved at $-80^{\circ} \mathrm{C}$ for later analyses. All analyses will be performed at a central laboratory in Oslo, Norway. Standard inflammatory cytokines/chemokines and complement activation will be measured as previously described [18].

- Measurements of donor-specific antibodies: The human leukocyte antigen (HLA) antibody status and the presence of donor-specific HLA antibodies (DSA) before transplantation and produced de novo at 4 weeks, 3 and 12 months, and 2 and 3 years post-transplantation will be analyzed using standard methodology already in use in the tissue typing lab at Sahlgrenska University Hospital. All tests will be performed in one laboratory to avoid interlaboratory variation. Collected samples will be stored at $-80^{\circ} \mathrm{C}$ for additional analyses if new tests for other antigens appear on the market.

- Functional assessments: A 6-minute walk test (6MWT) is a functional test that may be performed in the hallway or on the treadmill in a standardized manner.

- Quality of life assessments: Two standardized questionnaires, EQ5D3L and The St. George's Respiratory Questionnaire (SGRQ), will be used. Measurements will be done prior to LTx and 1, 2, and 3 years after lung transplantation.

- NODAT/PTDM: New-onset diabetes after transplantation (NODAT) or post- transplantation diabetes mellitus (PTDM) [19] will be assessed by oral glucose tolerance test (OGTT) pre-Tx and at 6, 12, 24, and 36 months after transplantation.

\section{RESULTS}

\section{Safety Assessment}

Treatment with tacrolimus versus cyclosporine has been shown to be safe and comparable regarding early outcome such as rejection rates and early mortality, as outlined in our literature review [20]. However, there are few comprehensive studies and data on long-term outcome, particularly on CLAD, is scarce.

Safety assessments will consist of monitoring and recording all infections, any malignancies, AEs, SAEs, and suspected unexpected serious adverse reactions (SUSARs), the regular monitoring of hematology, blood chemistry, physiological testing, and regular measurement of vital signs. To ensure patient safety, every SAE, regardless of suspected causality, occurring after the patient is randomized and until 4 weeks after the patient has stopped study participation must be reported to the sponsor within $24 \mathrm{~h}$ or at first possible weekday of learning of its occurrence, whichever comes first.

\section{Sample Size and Power Calculation}

In order to detect a difference in CLAD between the two treatment groups in the ScanCLAD study, we calculated our sample size according to the following assumptions: 2-year inclusion, 3-year follow-up, $80 \%$ power, and two-sided significance level of $5 \%$. On the basis of these assumptions, the numbers needed were calculated as follows: CLAD incidence in CyA and Tac arm of 30\% (BOS alone approximately 30\% at 3 years [4] with cyclosporine) and 15\% (50\% reduction was seen in the Treede study [3] with Tac, although from $22 \%$ to $11 \%$ ), respectively, and $30 \%$ censuring (early dropouts) which would require 121 patients in each arm, altogether 242 patients in the study. 


\section{Statistical Analyses}

A statistical analysis plan (SAP) was written and approved by the ethics committees (EC). All analyses and tabulations will be performed using the latest release of Stata software statistical program (currently version 14.0). The analysis will be done when all patients have completed the trial at 36 months after LTx (or discontinued prematurely). Unless otherwise stated, all statistical tests will be two-sided and use the $5 \%$ level of statistical significance. Confidence intervals will be presented with $95 \%$ as the level of confidence. All summary statistics will be presented for the treatment groups. Frequency distributions will be provided for categorical variables and the two treatment groups will be compared with the chi-square or Fisher's exact test. Descriptive statistics of mean, standard deviation, minimum, median and maximum will be presented for continuous variables; comparison of the two treatment groups will be performed with suitable chosen two-sample tests. Time to event data including rates of affected patients will be assessed by Kaplan-Meier statistics and compared between the two groups with the log rank test. Cumulative incidence will also be analyzed by competing risk methods when competing risks are present and will be compared between the two groups with the Fine and Gray's test or similar test. Data from all centers that participate in this study will be combined.

\section{Populations for Analysis}

The enrolled patient (ENR) population will include all patients who signed an informed consent regardless of whether lung transplantation was performed or not.

The intention-to-treat (ITT) population will consist of all randomized patients. The ITT population will be analyzed following the ITT principle. However, this analysis is not the main analysis of the study, since some patients will inevitably be sent home without transplantation because of worsening of donor organ function or other reasons, explained by the fact that randomization occurs prior to transplantation. The ITT population will therefore include patients who never underwent transplantation or received study drug.

The most important populations of study to analyze are the following:

- The per protocol transplanted ( $\left.\mathrm{PP}_{\text {trans }}\right)$ population will consist of all patients in whom transplantation was performed and who were randomized and treated with at least one dose of randomized treatment. The $\mathrm{PP}_{\text {trans }}$ population is also the safety population (SAF).

- The per protocol CLAD (PP $\mathrm{PLAD}_{\mathrm{C}}$ ) population (or full-analysis set population, FAS) will consist of all randomized patients who received at least one dose of any immunosuppressive therapy, underwent transplantation, and had at least one post-baseline assessment of the primary efficacy variable (CLAD). Randomized patients without data on the primary outcome variable will be excluded from this population.

- The per protocol drug $\left(\mathrm{PP}_{\mathrm{drug}}\right)$ population will consist of all ITT patients who did not show major deviations from the protocol procedures that may have an impact on the study outcome, remained on randomized study drug, and who have completed the treatment phase at 36 months according to protocol.

\section{Interim Analysis}

There will be no planned interim analysis initiated by the steering committee; however, if the data and safety monitoring board (DSMB) wants one performed it can be done blinded.

\section{Data Management}

\section{Randomization}

The eCRF software creates the enrollment and randomization numbers at enrollment and randomization visits, respectively. Randomization is performed using a web-based system and patients are randomized in a 1:1 ratio to one of the two treatment groups. Two sets of randomization numbers will be prepared for stratified randomization: (1) patients with a 
diagnosis of cystic fibrosis and (2) patients without a diagnosis of cystic fibrosis.

\section{Site Monitoring}

During the study, a field monitor will visit the site regularly to check the completeness of patient records, the accuracy of entries in the eCRFs, the adherence to the protocol and Good Clinical Practice (GCP), and the progress of enrollment. Monitoring standards are followed and all checks of the consistency of the source data with the CRFs are performed according to the study-specific monitoring plan.

\section{Data Collection}

Gothia Forum, a non-profit organization associated with Gothenburg University and Sahlgrenska University Hospital, assists the sponsor (GD) and all PIs in organizing the study according to GCP rules. The study database is placed on a central internet server. Designated investigator staff will enter the data required by the protocol into the database. Automatic validation programs check for data discrepancies in the eCRFs and, by generating appropriate error messages, allow modification or verification of the entered data by the investigator staff before being saved in the database.

\section{Database Management and Quality Control}

Gothia Forum will review the eCRFs entered by investigational staff for completeness and accuracy and instruct the site personnel to make any required corrections or additions.

\section{DISCUSSION}

In brief, CLAD is currently defined as an irreversible drop in FEV1 to below $80 \%$ of baseline FEV1 after LTx. In recent studies RAS seems to account for approximately $30 \%$ of all CLAD and BOS for the remaining 70\% [6]. For qualifying as RAS, lung function measurements also need to show restrictive physiology, defined as an irreversible decline in TLC to below $90 \%$ of the baseline TLC $[6,7,21]$. CLAD is one of the most common causes of long-term deaths according to the ISHLT registry [22].
A Cochrane review on tacrolimus use was performed 6 years ago by the Copenhagen group and showed that tacrolimus may be superior to cyclosporine regarding BOS, treatment withdrawal, and arterial hypertension, but may be inferior regarding development of diabetes. No difference in mortality and acute rejection was observed between patients treated with tacrolimus and cyclosporine [20].

CNIs, such as tacrolimus or cyclosporine, are the cornerstones of immunosuppressive protocols worldwide in LTx. There are well-known side effects of these drugs, such as nephrotoxicity and an increased incidence of diabetes, cardiovascular morbidity, and malignancy. All centers are using CNIs after LTx; however, in the last decade a switch has occurred worldwide from cyclosporine to tacrolimus, according to the ISHLT registry [4]. This change has occurred even though there have been no real proof-ofconcept studies confirming that tacrolimus is superior to cyclosporine with respect to longterm survival after LTx. Controversy has existed whether or not tacrolimus would result in fewer rejections over time as indicated by registry data but so far not shown in properly designed studies in LTx patients. Therefore, cyclosporine is still the CNI of choice in all Scandinavian lung transplant programs. However, recently a European-Australian prospective randomized study showed that tacrolimus had a lower incidence of BOS in LTx, after a 3-year follow-up [3]. The incidence of BOS decreased from approximately $21 \%$ to $11 \%$ at 3 years, despite the fact that considerably more patients crossed over from the cyclosporine group to the tacrolimus group than vice versa. However, there was no significant difference in survival between the groups, which might have been related to the high rate of crossover. We expect a lower crossover rate in the Scandinavian study, compared to Treede et al., which may impact survival if there is a true difference between the studied drugs. In addition, our aim is to include all adult patients eligible for de novo double lung transplantation and without exclusion criteria, in order to have minimal selection bias and achieve a generalizable study in lung transplantation. The ScanCLAD study has caused synchronized programs in all 


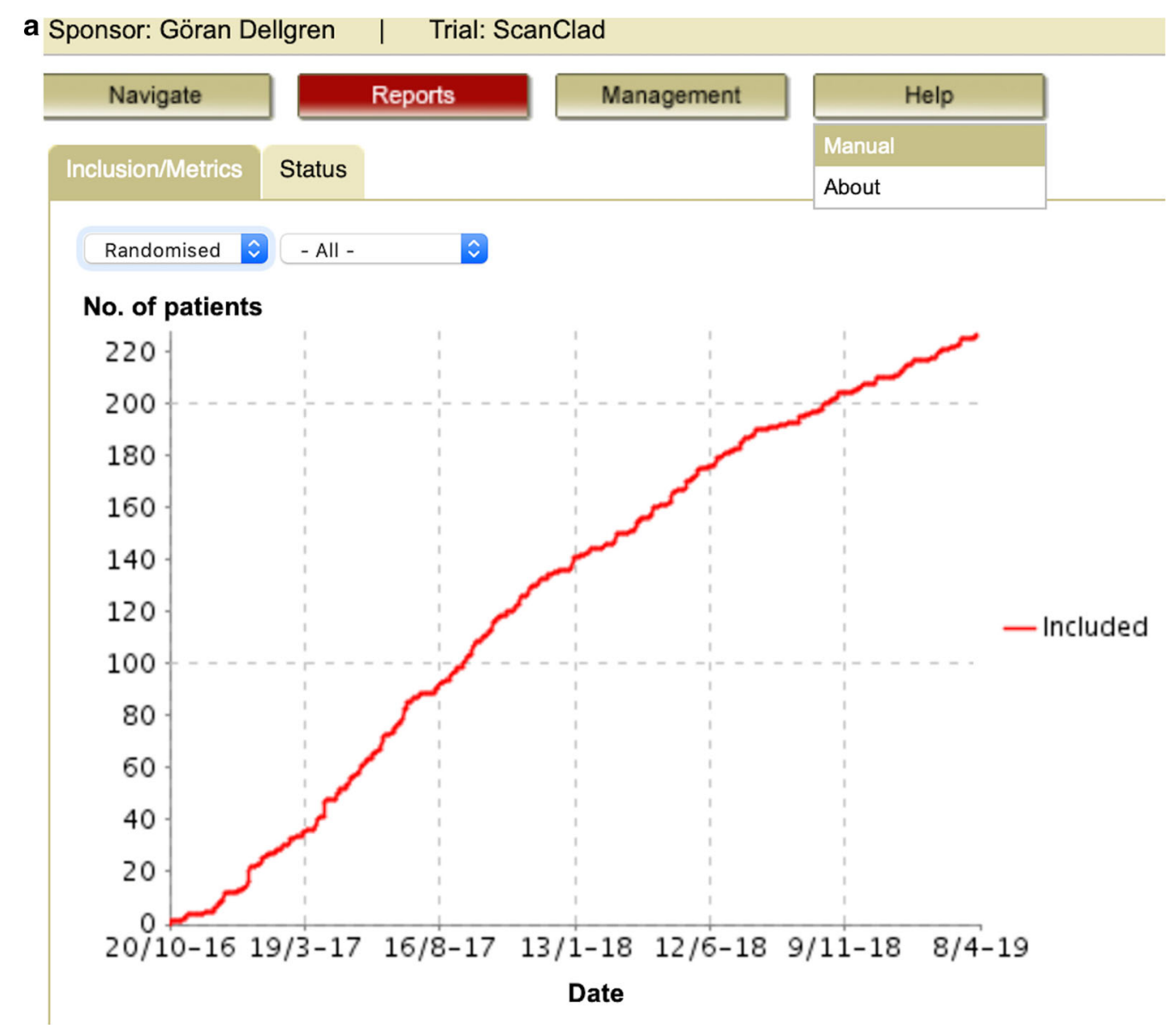

\begin{tabular}{|l|r|r|}
\multicolumn{1}{|c|}{ Site } & Enrolled patients & Randomised patients \\
\hline All & 354 & 227 \\
\hline 1 Gothenburg & 80 & 67 \\
\hline 2 Lund & 43 & 23 \\
\hline 3 Copenhagen & 74 & 55 \\
\hline 4 Oslo & 82 & 39 \\
\hline 5 Helsinki & 75 & 43 \\
\hline
\end{tabular}

Fig. 2 Randomized patients at the end of April 2019 and stratified by center in the ScanCLAD study. GOT = Gothenburg, Sweden; Lund = Lund, Sweden; CPH = Copenhagen, Denmark; HELS = Helsinki, Finland; and OSLO = Oslo, Norway

Scandinavian lung transplant centers (five centers in four countries) both with regard to treatment and examinations. We stand more united with more than 150 lung transplantations per year.

In conclusion, we believe that clinical equipoise still exists regarding which CNI that should be used after lung transplantation, and that registry data and the few studies available suffer from bias. In an attempt to improve the low level of evidence, we have begun an investigator-initiated RCT regarding the preferred CNI after LTx. 


\section{Strengths and Limitations of the Study}

This multicenter, randomized, open-label study called the ScanCLAD study aims to include most adult patients undergoing double lung transplantation, and hopefully will add evidence on which CNI will result in less CLAD after lung transplantation. Not many studies have been conducted on the choice of CNI in de novo lung-transplanted patients, and this one is also designed with a number of substudies. The strengths of this study are that in a randomized controlled fashion two drugs preventing rejection are compared regarding long-term CLAD at 3 years among five centers having the same protocol after lung transplantation. Unlike previous studies, ours will also comply with the modern definition of CLAD. Furthermore, we will have an adjudication committee regarding the main outcome CLAD. Potential limitations are the usual ones associated with a randomized controlled study and also that it is not a doubleblind study, and therefore may introduce bias.

\section{Current Study Status}

The study was initiated in November 2016 in Gothenburg, and subsequently all other sites were started in sequence with the last one up and running in July 2017. Since then 227 patients have been randomized (Fig. 2). Four amendments to the study protocol have been filed so far and approved by the EC in all countries. The study is followed by a DSMB group, consisting of Andrew Fisher, Jens Gottlieb, Eric Verschuuren, and Hans Wedel, that oversees the study and meets every 6 months. We are currently meeting our expected inclusion rate and anticipate randomizing the last patient sometime after the summer of 2019. The planned last patient visit will be in 2022 .

\section{ACKNOWLEDGEMENTS}

We thank all colleagues, staff, coordinators, and nurses that enthusiastically participated and made the study possible. A special thanks to retired senior consultant Martin Iversen for his participation in developing this study.

Funding. This work is supported by grants from Astellas A/S, the Swedish Heart and Lung Foundation, The Scandiatransplant Organization, and The Heart Centre Research Committee of Rigshospitalet Denmark. The Rapid Service Fee was funded by the authors.

Authorship. All authors meet the International Committee of Medical Journal Editors (ICMJE) criteria for authorship for this article, take responsibility for the integrity of the work as a whole, and have given their approval for this version to be published.

Disclosures. Göran Dellgren (sponsor of the study) who has research grants from Astellas A/S for the ScanCLAD study (partially but not fully funded by the company) and from Abbott regarding a destination therapy study on LVAD (the SweVAD study). Thomas Kromann Lund, Peter Raivio, Inga Leuckfeld, Johan Svahn, Jesper Magnusson, and Gerdt C. Riise have nothing to disclose.

Compliance with Ethics Guidelines. This multicenter study was first approved by the Ethics Review Board (D.nr 154-16) at the University of Gothenburg as well as by the Medical Product Agency in Sweden (EUDRACT number 2015-004137-27, D.nr 5.1 2016-31518), and subsequently by the corresponding authorities in Denmark, Finland, and Norway. Therefore, ethics committees (EC) of all the Scandinavian countries have approved the final study protocol, including the final version of the informed consent form, and the following amendments of the protocol, including all substudies. In addition, medical product agencies in all four participating countries have approved the study. Written informed consent will be obtained before any study-related procedures are implemented. The study will be performed in accordance with ethical principles that have their origin in the Declaration of Helsinki and are consistent with ICH-GCP and applicable local regulatory requirements. The study was registered at ClinicalTrial.gov 
(NCT02936505) well before the first patient was included in the study.

Open Access. This article is licensed under a Creative Commons Attribution-NonCommercial 4.0 International License, which permits any non-commercial use, sharing, adaptation, distribution and reproduction in any medium or format, as long as you give appropriate credit to the original author(s) and the source, provide a link to the Creative Commons licence, and indicate if changes were made. The images or other third party material in this article are included in the article's Creative Commons licence, unless indicated otherwise in a credit line to the material. If material is not included in the article's Creative Commons licence and your intended use is not permitted by statutory regulation or exceeds the permitted use, you will need to obtain permission directly from the copyright holder. To view a copy of this licence, visit http://creativecommons.org/licenses/by$\mathrm{nc} / 4.0 /$.

\section{REFERENCES}

1. Gilljam M, Nyström U, Dellgren G, Skog I, Hansson L. Survival after lung transplantation for cystic fibrosis in Sweden. Eur J Cardiothorac Surg. 2017;51:571-6.

2. Fakhro M, Ingemansson R, Skog I, et al. 25-year follow-up after lung transplantation at Lund University Hospital in Sweden: superior results obtained for patients with cystic fibrosis. Interact Cardiovasc Thorac Surg. 2016;23:65-73.

3. Treede H, Glanville AR, Klepetko W, et al. Tacrolimus and cyclosporine have differential effects on the risk of development of bronchiolitis obliterans syndrome: results of a prospective, randomized international trial in lung transplantation. J Heart Lung Transpl. 2012;31:797-804.

4. Chambers DC, Yusen RD, Cherikh WS, et al. The registry of the International Society for Heart and Lung Transplantation: thirty-fourth adult lung and heart-lung transplantation report-2017; focus theme: allograft ischemic time. J Heart Lung Transpl. 2017;36:1047-59.

5. Verleden GM, Raghu G, Meyer KC, Glanville AR, Corris P. A new classification system for chronic lung allograft dysfunction. J Heart Lung Transpl. 2014;33:127-33.

6. Glanville AR, Verleden GM, Todd JL, et al. Chronic lung allograft dysfunction: definition and update of restrictive allograft syndrome-a consensus report from the pulmonary council of the ISHLT. J Heart Lung Transplant. 2019;38(5):483-92.

7. Verleden GM, Glanville AR, Lease ED, et al. Chronic lung allograft dysfunction: definition, diagnostic criteria, and approaches to treatment-a consensus report from the pulmonary council of the ISHLT. J Heart Lung Transpl. 2019;38(5):493-503.

8. Miller MR, Hankinson J, Brusasco V, et al. ATS/ERS Task Force: standardisation of lung function testing-standardisation of spirometry. Eur Respir J. 2005;26:319-38.

9. Wanger JL, Clausen A, Coates OF, et al. ATS/ERS Task Force: standardisation of lung function testing-standardisation of the measurement of lung volumes. Eur Respir J. 2005;26:511-22.

10. MacIntyre N, Crapo RO, Viegi G, et al. ATS/ERS Task Force: standardisation of lung function testing-standardisation of the single-breath determination of carbon monoxide uptake in the lung. Eur Respir J. 2005;26:720-35.

11. Kolsrud O, Ricksten SE, Holmberg E, et al. Measured and not estimated GFR should be used to assess renal function in heart transplant recipients. Nephrol Dial Transpl. 2016;31:1182-9.

12. Levey AS, Bosch JP, Lewis JB, Greene T, Rogers N, Roth D. A more accurate method to estimate glomerular filtration rate from serum creatinine: a new prediction equation. Modification of Diet in Renal Disease Study Group. Ann Intern Med. 1999;130:461-70.

13. Rodrigo E, Fernández-Fresnedo G, Ruiz JC, et al. Assessment of glomerular filtration rate in transplant recipients with severe renal insufficiency by Nankivell, Modification of Diet in Renal Disease (MDRD), and Cockroft-Gault equations. Transpl Proc. 2003;35:1671-2.

14. Stewart S, Fishbein MC, Snell GI, et al. Revision of the 1996 working formulation for the standardization of nomenclature in the diagnosis of lung rejection. J Heart Lung Transpl. 2007;26:1229-42.

15. Snell GI, Yusen RD, Weill D, et al. Report of the ISHLT working group on primary lung graft dysfunction, part I: definition and grading-a 2016 consensus group statement of the International Society for Heart and Lung Transplantation. J Heart Lung Transpl. 2017;36:1097-103. 
16. Belmaati EO, Steffensen I, Jensen C, et al. Radiological patterns of primary graft dysfunction after lung transplantation evaluated by 64 -multi-slice computed tomography: a descriptive study. Interact Cardiovasc Thorac Surg. 2012;14:785-91.

17. Belmaati EO, Jensen C, Kofoed KF, Iversen M, Steffensen I, Nielsen MB. Primary graft dysfunction: possible evaluation by high resolution computed tomography, and suggestions for a scoring system. Interact Cardiovasc Thorac Surg. 2009;9:859-67.

18. Auråen $\mathrm{H}$, Mollnes TE, Bjortuft $\mathrm{O}$, et al. Multiorgan procurement increases systemic inflammation in brain dead donors. Clin Transpl. 2013;27:613-8.

19. First MR, Dhadda S, Fitzsimmons W, Croy R, Holman J, Fitzsimmons WE. New-onset diabetes after transplantation (NODAT): an evaluation of definitions in clinical trials. Transplantation. 2013;96:58-64.

20. Penninga L, Penniga EL, Møller $\mathrm{CH}$, Iversen $\mathrm{M}$, Steinbrüchel D, Gluud C. Tacrolimus versus cyclosporine as primary immunosuppression for lung transplant recipients. Cochrane Database Syst Rev. 2013;5:CD008817.

21. Sato M, Waddell TK, Wagnetz U, et al. Restrictive allograft syndrome (RAS): a novel form of chronic lung allograft dysfunction. J Heart Lung Transpl. 2011;30:735-42.

22. Christie JD, Edwards LB, Aurora P, et al. The registry of the International Society for Heart and Lung Transplantation: twenty-sixth official adult lung and heart-lung transplantation report-2009. J Heart Lung Transpl. 2009;28:1031-49. 